\title{
$N$-fixed point theorems for nonlinear contractions in partially ordered metric spaces
}

\author{
Mohadeseh Paknazar ${ }^{1 *}$, Madjid Eshaghi Gordji², Manuel De La Sen ${ }^{3}$ and Seyed Mansour Vaezpour ${ }^{4}$
}

\section{"Correspondence:}

m.paknazar@yahoo.com

'Department of Mathematics,

Science and Research Branch,

Islamic Azad University, Tehran, Iran

Full list of author information is

available at the end of the article

\begin{abstract}
In present paper we introduce the concept of a new g-monotone mapping and define the notions of $n$-fixed point and $n$-coincidence point and prove some related theorems for nonlinear contractive mappings in partially ordered complete metric spaces. Our results are generalization of the main results of Lakshmikantham and Ćirić (Nonlinear Anal. 70:4341-4349, 2009) and include several recent developments. Moreover, we give an example to support our results.
\end{abstract}

MSC: Primary 47H10; secondary 54H25; 34B15

Keywords: partially ordered set; fixed point; contractive mapping

\section{Introduction and preliminaries}

The notion of a coupled fixed point is introduced by Bhaskar and Lakshmikantham [1]. Afterward Lakshmikantham and Cirić in [2] extended this notion by defining the $g$ monotone property in partially ordered spaces. For other results on coupled coincidence and coupled common fixed point theory, we refer the readers to ([3-8]). Many authors obtained important results for usual coincidence and common fixed points in partially ordered spaces (see, for instance, [9-13]). Recently, Berinde and Borcut [14, 15] introduced the concept of a tripled fixed point. Other authors obtained important results in this area (see, for instance, [8, 9]). Very recently Eshaghi and Ramezani [16] introduced and investigated the concept of an $n$-fixed point (see also Def. 2.7 [4]).

From now, $(X, \leq, d)$ is a partially ordered complete metric space. Further, the product space $X^{2}=X \times X$ has the following partial order:

$$
(u, v) \leq(x, y) \quad \Leftrightarrow \quad x \geq u, \quad y \leq v \quad \text { for all }(x, y),(u, v) \in X \times X .
$$

We summarize in the following the basic notions and results established in $[1,2,14]$.

Definition 1.1 (See [1]) A mapping $F: X \times X \rightarrow X$ is said to have the mixed monotone property if $F(x, y)$ is monotone non-decreasing in $x$ and is monotone non-increasing in $y$, that is, for any $x, y \in X$,

$$
\begin{array}{lll}
x_{1} \leq x_{2} \quad \Rightarrow \quad F\left(x_{1}, y\right) \leq F\left(x_{2}, y\right) & \text { for } x_{1}, x_{2} \in X, \\
y_{1} \leq y_{2} \quad \Rightarrow \quad F\left(x, y_{2}\right) \leq F\left(x, y_{1}\right) & \text { for } y_{1}, y_{2} \in X .
\end{array}
$$

○ 2013 Paknazar et al.; licensee Springer. This is an Open Access article distributed under the terms of the Creative Commons Attribution License (http://creativecommons.org/licenses/by/2.0), which permits unrestricted use, distribution, and reproduction in any medium, provided the original work is properly cited. 
Definition 1.2 (See [1]) An element $(x, y) \in X \times X$ is said to be a coupled fixed point of the mapping $F: X \times X \rightarrow X$ if $F(x, y)=x$ and $F(y, x)=y$.

Theorem 1.3 (See [1]) Let $F: X \times X \rightarrow X$ be a mapping having the mixed monotone property on $X$. Assume that there exists $k \in[0,1)$ with

$$
d(F(x, y), F(u, v)) \leq \frac{k}{2}(d(x, u)+d(y, v)) \quad \text { for each } x \leq u, y \geq v .
$$

Also suppose either

(a) $F$ is continuous, or

(b) $X$ has the following property:

(i) If a non-decreasing sequence $\left\{x_{n}\right\} \rightarrow x$, then $x_{n} \leq x$ for all $n$;

(ii) If a non-increasing sequence $\left\{y_{n}\right\} \rightarrow y$, then $y_{n} \geq y$ for all $n$.

If there exist $x_{0}, y_{0} \in X$ such that $x_{0} \leq F\left(x_{0}, y_{0}\right)$ and $y_{0} \geq F\left(y_{0}, x_{0}\right)$, then $F$ has a coupled fixed point.

Inspired by Definition 1.1, Lakshmikantan and Ćirić [2] introduced the following concept of mixed $g$-monotone mappings.

Definition 1.4 (See [2]) Let $F: X \times X \rightarrow X$ and $g: X \rightarrow X$ be mappings. $F$ is said to have the mixed $g$-monotone property if $F$ is monotone g-non-decreasing in its first argument and is monotone $g$-non-increasing in its second argument, that is, for any $x, y \in X$,

$$
\begin{array}{lll}
g\left(x_{1}\right) \leq g\left(x_{2}\right) \quad \Rightarrow \quad F\left(x_{1}, y\right) \leq F\left(x_{2}, y\right) & \text { for } x_{1}, x_{2} \in X, \\
g\left(y_{1}\right) \leq g\left(y_{2}\right) \quad \Rightarrow \quad F\left(x, y_{1}\right) \geq F\left(x, y_{2}\right) & \text { for } y_{1}, y_{2} \in X .
\end{array}
$$

It is clear that Definition 1.4 reduces to Definition 1.1 when $g$ is an identity mapping.

Definition 1.5 (See [2]) An element $(x, y) \in X \times X$ is called a coupled coincidence point of the mapping $F: X \times X \rightarrow X$ and $g: X \rightarrow X$ if $F(x, y)=g(x)$ and $F(y, x)=g(y)$.

Definition 1.6 (See [2]) Let $F: X \times X \rightarrow X, g: X \rightarrow X$ be mappings. We say that $F$ and $g$ are commutative if $g(F(x, y))=F(g(x), g(y))$ for all $x, y \in X$.

Theorem 1.7 (See [2]) Assume that there is a function $\varphi:[0,+\infty) \rightarrow[0,+\infty)$ with $\varphi(t)<t$ and $\lim _{r \rightarrow t^{+}} \varphi(r)<t$ for each $t>0$, and also suppose that $F: X \times X \rightarrow X$ and $g: X \rightarrow X$ are mappings such that $F$ has the mixed $g$-monotone property and

$$
d(F(x, y), F(u, v)) \leq \varphi\left(\frac{d(g(x), g(u))+d(g(y), g(v))}{2}\right)
$$

for all $x, y, u, v \in X$, for which $g(x) \leq g(u)$ and $g(y) \geq g(v)$.

Suppose that $F(X \times X) \subseteq g(X), g$ is continuous and commutes with $F$, and also suppose that either

(a) $F$ is continuous, or

(b) $X$ has the following property: 
(i) If a non-decreasing sequence $\left\{x_{n}\right\} \rightarrow x$, then $x_{n} \leq x$ for all $n$;

(ii) If a non-increasing sequence $\left\{y_{n}\right\} \rightarrow y$, then $y \leq y_{n}$ for all $n$.

If there exist $x_{0}, y_{0} \in X$ such that $g\left(x_{0}\right) \leq F\left(x_{0}, y_{0}\right)$ and $g\left(y_{0}\right) \geq F\left(y_{0}, x_{0}\right)$, then there exist $x, y \in X$ such that $g(x)=F(x, y)$ and $g(y)=F(y, x)$, i.e., $F$ and $g$ have a coupled coincidence point.

Theorem 1.8 (See [2]) In addition to the hypothesis of Theorem 1.7, suppose that for every $(x, y),\left(x^{*}, y^{*}\right) \in X \times X$, there exists $(u, v) \in X \times X$ such that $(F(u, v), F(v, u))$ is comparable to $(F(x, y), F(y, x))$ and $\left(F\left(x^{*}, y^{*}\right), F\left(y^{*}, x^{*}\right)\right)$. Then $F$ and $g$ have a unique coupled common fixed point, i.e., there exists a unique $(x, y) \in X \times X$ such that

$$
x=g(x)=F(x, y), \quad y=g(y)=F(y, x) .
$$

Recently, Berinde and Borcut [14] introduced the following partial order on the product space $X^{3}=X \times X \times X$ :

$$
(x, y, z) \leq(u, v, w) \quad \Leftrightarrow \quad x \leq u, \quad y \geq v, \quad z \leq w
$$

where $(x, y, z),(u, v, w) \in X^{3}$ (see also [15]).

Definition 1.9 (See [14]) Let $F: X^{3} \rightarrow X$ be a mapping. We say that $F$ has the mixed monotone property if $F(x, y, z)$ is monotone non-decreasing in $x$ and $z$, and it is monotone non-increasing in $y$, i.e., for any $x, y, z \in X$,

$$
\begin{array}{lll}
x_{1}, x_{2} \in X, \quad x_{1} \leq x_{2} & \Rightarrow \quad F\left(x_{1}, y, z\right) \leq F\left(x_{2}, y, z\right), \\
y_{1}, y_{2} \in X, \quad y_{1} \leq y_{2} \quad \Rightarrow \quad F\left(x, y_{1}, z\right) \geq F\left(x, y_{2}, z\right), \\
y z_{1}, z_{2} \in X, \quad z_{1} \leq z_{2} \quad \Rightarrow \quad F\left(x, y, z_{1}\right) \leq F\left(x, y, z_{2}\right) .
\end{array}
$$

Definition 1.10 (See [14]) An element $(x, y, z) \in X^{3}$ is called a tripled fixed point of $F$ : $X^{3} \rightarrow X$ if

$$
F(x, y, z)=x, \quad F(y, x, y)=y, \quad F(z, y, x)=z .
$$

Theorem 1.11 (See [14]) Let $F: X^{3} \rightarrow X$ have the mixed monotone property on $X$. Assume that there exist constants $j, k, l \in[0,1)$ with $j+k+l<1$, for which

$$
d(F(x, y, z), F(u, v, w)) \leq j d(x, u)+k d(y, v)+l d(z, w) \quad \forall x \geq u, y \leq v, z \geq w .
$$

\section{Also suppose either}

(a) $F$ is continuous, or

(b) $X$ has the following property:

(i) If a non-decreasing sequence $\left\{x_{n}\right\} \rightarrow x$, then $x_{n} \leq x$ for all $n$;

(ii) If a non-increasing sequence $\left\{y_{n}\right\} \rightarrow y$, then $y_{n} \geq y$ for all $n$. 
If there exist $x_{0}, y_{0}, z_{0} \in X$ such that

$$
x_{0} \leq F\left(x_{0}, y_{0}, z_{0}\right), \quad y_{0} \geq F\left(y_{0}, x_{0}, y_{0}\right) \quad \text { and } \quad z_{0} \leq F\left(z_{0}, y_{0}, x_{0}\right) \text {, }
$$

then there exist $x, y, z \in X$ such that

$$
x=F(x, y, z), \quad y=F(y, x, y), \quad z=F(z, y, x) .
$$

The following concept of an $n$-fixed point was introduced by Eshaghi and Ramezani [16]. We suppose, as in [16], that $k$ is a positive integer (odd or even) and that the product space $X^{k}=\underbrace{X \times \cdots \times X}_{k \text {-times }}$ is endowed with following partial order: for $\left(x_{1}, x_{2}, \ldots, x_{k}\right)$,

$$
\begin{gathered}
\left(\left(y_{1}, y_{2}, \ldots, y_{k}\right) \in X^{k},\left(x_{1}, x_{2}, \ldots, x_{k}\right) \leq\left(y_{1}, y_{2}, \ldots, y_{k}\right)\right) \\
\Longleftrightarrow \quad\left(\left(x_{2 i-1} \leq y_{2 i-1}\right) \text { for all } i \in 1,2, \ldots,\left[\frac{k+1}{2}\right],\right. \\
\left.x_{2 i} \geq y_{2 i} \text { for all } i \in 1,2, \ldots,\left[\frac{k}{2}\right]\right)
\end{gathered}
$$

Definition 1.12 (See [16]) An element $\left(x_{1}, x_{2}, \ldots, x_{k}\right) \in X^{k}$ is called a $k$-fixed point of $F$ : $X^{k} \rightarrow X$ if

$$
x_{i}=F\left(x_{i}, x_{i-1}, \ldots, x_{2}, x_{1}, x_{2}, \ldots, x_{k-i+1}\right) \quad \text { for all } i \in\{1,2, \ldots, k\}
$$

Theorem 1.13 (See [16]) Let $F: X^{k} \rightarrow X$ be a continuous mapping having the mixed monotone property on $X$. Assume that there exist $\left\{j_{i}\right\}_{i \in \mathbb{Z}} \in[0,1)$ with $\sum_{i=-\infty}^{i=\infty} j_{i}<1$ and $j_{i}=0$ for all $i \neq\{1,2, \ldots, k\}$ such that

$$
d\left(F\left(x_{1}, x_{2}, \ldots, x_{k}\right), F\left(y_{1}, y_{2}, \ldots, y_{k}\right)\right) \leq j_{1} d\left(x_{1}, y_{1}\right)+j_{2} d\left(x_{2}, y_{2}\right)+\cdots+j_{k} d\left(x_{k}, y_{k}\right)
$$

for all $x_{i}, y_{i} \in X(i \in\{1,2, \ldots, k\})$, for which $x_{2 i-1} \geq y_{2 i-1}$ for all $i \in\left\{1,2, \ldots,\left[\frac{k+1}{2}\right]\right\}$ and $x_{2 i} \leq$ $y_{2 i}$ for all $i \in\left\{1,2, \ldots,\left[\frac{k-1}{2}\right]\left(\left[\frac{k}{2}\right]\right)\right\}$.

If there exist $x_{1}^{0}, x_{2}^{0}, \ldots, x_{k}^{0} \in X$ such that

$$
x_{2 i-1}^{0} \leq F\left(x_{2 i-1}^{0}, x_{2 i-2}^{0}, \ldots, x_{2}^{0}, x_{1}^{0}, x_{2}^{0}, \ldots, x_{k-2 i+2}^{0}\right)
$$

for all $i \in\left\{1,2, \ldots,\left[\frac{k+1}{2}\right]\right\}$ and

$$
x_{2 i}^{0} \geq F\left(x_{2 i}^{0}, x_{2 i-1}^{0}, \ldots, x_{2}^{0}, x_{1}^{0}, x_{2}^{0}, \ldots, x_{k-2 i+1}^{0}\right)
$$

for all $i \in\left\{1,2, \ldots,\left[\frac{k}{2}\right]\right\}$, then $F$ has a $k$-fixed point.

In this paper, we present the new $k$-fixed point, and by defining the notion of a new $g$-monotone mapping, the existence of a $k$-coincidence point and the uniqueness of a common $k$-fixed point are obtained. Our definitions are thoroughly different from the ones in $[14,15]$. 


\section{The main results}

Definition 2.1 Let $X$ be a non-empty set, and let $F: X^{k} \rightarrow X$ be a given mapping $(k \geq 2)$. An element $\left(x_{1}, x_{2}, x_{3}, \ldots, x_{k}\right) \in X^{k}$ is said to be a $k$-fixed point of the mapping $F$ if

$$
\begin{aligned}
& F\left(x_{1}, x_{2}, \ldots, x_{k-1}, x_{k}\right)=x_{1}, \\
& F\left(x_{2}, x_{3}, \ldots, x_{k}, x_{1}\right)=x_{2}, \\
& \vdots \\
& F\left(x_{k}, x_{1}, x_{2}, \ldots, x_{k-1}\right)=x_{k} .
\end{aligned}
$$

\section{Definition 2.2}

Let $X$ be a non-empty set, and let $g: X \rightarrow X$ and $F: X^{k} \rightarrow X(k \geq 2)$ be two given mappings. $F$ is said to have the new $g$-monotone property if $F$ is monotone $g$-non-decreasing in its first argument. That is, for any $\left(x_{1}, x_{2}, \ldots, x_{k}\right),\left(y_{1}, y_{2}, \ldots, y_{k}\right) \in X^{k}$,

$$
g\left(x_{1}\right) \leq g\left(y_{1}\right) \quad \Rightarrow \quad F\left(x_{1}, x_{2}, \ldots, x_{k}\right) \leq F\left(y_{1}, y_{2}, \ldots, y_{k}\right) .
$$

Definition 2.3 Let $X$ be a non-empty set, and let $g: X \rightarrow X$ and $F: X^{k} \rightarrow X(k \geq 2)$ be two given mappings. An element $\left(x_{1}, x_{2}, \ldots, x_{k}\right) \in X^{k}$ is called a $k$-coincidence point of $F: X^{k} \rightarrow X$ and $g: X \rightarrow X$ if

$$
\begin{aligned}
& g\left(x_{1}\right)=F\left(x_{1}, x_{2}, \ldots, x_{k-1}, x_{k}\right), \\
& g\left(x_{2}\right)=F\left(x_{2}, x_{3}, \ldots, x_{k}, x_{1}\right), \\
& \vdots \\
& g\left(x_{k}\right)=F\left(x_{k}, x_{1}, x_{2}, \ldots, x_{k-1}\right) .
\end{aligned}
$$

Note that if $g$ is an identity mapping, then Definition 2.3 reduces to Definition 2.1.

Definition 2.4 Let $X$ be a non-empty set, and let $g: X \rightarrow X$ and $F: X^{k} \rightarrow X(k \geq 2)$ be two given mappings. We say $F$ and $g$ are commutative if

$$
g\left(F\left(x_{1}, x_{2}, \ldots, x_{k}\right)\right)=F\left(g\left(x_{1}\right), g\left(x_{2}\right), \ldots, g\left(x_{k}\right)\right) \quad \text { for all } x_{1}, x_{2}, \ldots, x_{k} \in X
$$

Theorem 2.5 Let $(X, \leq, d)$ be a partially ordered complete metric space, and let $F: X^{k} \rightarrow$ $X$ and $g: X \rightarrow X$ be two given mappings such that $F$ has a new $g$-monotone property, $g$ is continuous, $F\left(X^{k}\right) \subset g(X)$ and $g$ commutes with $F$. Assume that there exists a continuous function $\varphi:[0,+\infty) \rightarrow[0,+\infty)$, satisfying

(i) $\varphi(t)<t$ for $t>0$ and $\varphi(0)=0$;

(ii) $\lim _{r \rightarrow t^{+}} \varphi(r)<t$ for each $t>0$, such that

$$
d\left(F\left(x_{1}, \ldots, x_{k}\right), F\left(y_{1}, \ldots, y_{k}\right)\right) \leq \varphi\left(\frac{d\left(g\left(x_{1}\right), g\left(y_{1}\right)\right)+\cdots+d\left(g\left(x_{k}\right), g\left(y_{k}\right)\right)}{k}\right)
$$


for all $x_{j}, y_{j}(j \in\{1,2, \ldots, k\})$ so that $g\left(x_{2 i-1}\right) \leq g\left(y_{2 i-1}\right)$ for all $i \in\left\{1,2, \ldots,\left[\frac{k+1}{2}\right]\right\}$ and $g\left(y_{2 i}\right) \leq$ $g\left(x_{2 i}\right)$ for all $i \in\left\{1,2, \ldots,\left[\frac{k}{2}\right]\right\}$, and suppose there exist $x_{1}^{0}, x_{2}^{0}, \ldots, x_{k}^{0} \in X$ such that

$$
\begin{aligned}
& g\left(x_{2 i-1}^{0}\right) \leq F\left(x_{2 i-1}^{0}, x_{2 i}^{0}, \ldots, x_{k}^{0}, x_{1}^{0}, \ldots, x_{2 i-2}^{0}\right) \quad \text { for all } i \in\left\{1,2, \ldots,\left[\frac{k+1}{2}\right]\right\}, \\
& g\left(x_{2 i}^{0}\right) \geq F\left(x_{2 i}^{0}, x_{2 i+1}^{0}, \ldots, x_{k}^{0}, x_{1}^{0}, x_{2}^{0}, \ldots, x_{2 i-1}^{0}\right) \quad \text { for all } i \in\left\{1,2, \ldots,\left[\frac{k}{2}\right]\right\} .
\end{aligned}
$$

\section{Also suppose that either}

(a) $F$ is continuous, or

(b) $X$ has the following property:

(i) If a non-decreasing sequence $\left\{x_{n}\right\} \rightarrow x$, then $x_{n} \leq x$ for all $n$;

(ii) If a non-increasing sequence $\left\{y_{n}\right\} \rightarrow y$, then $y_{n} \geq y$ for all $n$.

Then there exist $x_{1}, x_{2}, \ldots, x_{k} \in X$ such that

$$
g\left(x_{i}\right)=F\left(x_{i}, x_{i+1}, \ldots, x_{n}, x_{1}, x_{2}, \ldots, x_{i-1}\right) \quad \text { for all } i \in\{1,2, \ldots, k\} .
$$

That is, $F$ and $g$ have a $k$-coincidence point.

Proof Since $F\left(X^{k}\right) \subset g(X)$, we can find an element $x_{i}^{n} \in X$ such that

$$
g\left(x_{i}^{n}\right)=F\left(x_{i}^{n-1}, x_{i+1}^{n-1}, \ldots, x_{k}^{n-1}, x_{1}^{n-1}, \ldots, x_{i-1}^{n-1}\right) \quad \text { for all } i \in\{1,2, \ldots, k\} .
$$

We claim that

$$
\begin{aligned}
& g\left(x_{2 i-1}^{n-1}\right) \leq g\left(x_{2 i-1}^{n}\right) \quad \text { for all } i \in\left\{1,2, \ldots,\left[\frac{k+1}{2}\right]\right\} \text { and } \\
& g\left(x_{2 i}^{n-1}\right) \geq g\left(x_{2 i}^{n}\right) \quad \text { for all } i \in\left\{1,2, \ldots,\left[\frac{k}{2}\right]\right\} .
\end{aligned}
$$

We prove (2.5) by induction. Note that by $(2.2),(2.4)$ we have

$$
\begin{gathered}
g\left(x_{2 i-1}^{0}\right) \leq F\left(x_{2 i-1}^{0}, x_{2 i}^{0}, \ldots, x_{k}^{0}, x_{1}^{0}, \ldots, x_{2 i-2}^{0}\right)=g\left(x_{2 i-1}^{1}\right) \\
\text { for all } i \in\left\{1,2, \ldots,\left[\frac{k+1}{2}\right]\right\}
\end{gathered}
$$

and

$$
g\left(x_{2 i}^{0}\right) \geq F\left(x_{2 i}^{0}, x_{2 i+1}^{0}, \ldots, x_{k}^{0}, x_{1}^{0}, \ldots, x_{2 i-1}^{0}\right)=g\left(x_{2 i}^{1}\right) \quad \text { for all } i \in\left\{1,2, \ldots,\left[\frac{k}{2}\right]\right\} .
$$

Suppose that (2.5) is true for some $n$.

Due to the new $g$-monotone property of $F$, for $i \in\left\{1,2, \ldots,\left[\frac{k+1}{2}\right]\right\}$, we have

$$
\begin{aligned}
g\left(x_{2 i-1}^{n}\right) & =F\left(x_{2 i-1}^{n-1}, x_{2 i}^{n-1}, \ldots, x_{k}^{n-1}, x_{1}^{n-1}, \ldots, x_{2 i-2}^{n-1}\right) \\
& \leq F\left(x_{2 i-1}^{n}, x_{2 i}^{n}, \ldots, x_{k}^{n}, x_{1}^{n}, \ldots, x_{2 i-2}^{n}\right)=g\left(x_{2 i-1}^{n+1}\right),
\end{aligned}
$$


and for $i \in\left\{1,2, \ldots,\left[\frac{k}{2}\right]\right\}$, we have

$$
\begin{aligned}
g\left(x_{2 i}^{n}\right) & =F\left(x_{2 i}^{n-1}, x_{2 i+1}^{n-1}, \ldots, x_{k}^{n-1}, x_{1}^{n-1}, \ldots, x_{2 i-1}^{n-1}\right) \\
& \geq F\left(x_{2 i}^{n}, x_{2 i+1}^{n}, \ldots, x_{k}^{n}, x_{1}^{n}, \ldots, x_{2 i-1}^{n}\right)=g\left(x_{2 i}^{n+1}\right) .
\end{aligned}
$$

Thus (2.5) is true. We denote

$$
\delta_{n}:=d\left(g\left(x_{1}^{n}\right), g\left(x_{1}^{n+1}\right)\right)+d\left(g\left(x_{2}^{n}\right), g\left(x_{2}^{n+1}\right)\right)+\cdots+d\left(g\left(x_{k}^{n}\right), g\left(x_{k}^{n+1}\right)\right) .
$$

We will show that

$$
\delta_{n+1} \leq k\left(\varphi\left(\frac{\delta_{n}}{k}\right)\right) .
$$

By (2.1), (2.3) and (2.5), we have

$$
\begin{aligned}
d\left(g\left(x_{i}^{n+1}\right), g\left(x_{i}^{n+2}\right)\right)= & d\left(F\left(x_{i}^{n}, x_{i+1}^{n}, \ldots, x_{k}^{n}, x_{1}^{n}, \ldots, x_{i-1}^{n}\right),\right. \\
& \left.F\left(x_{i}^{n+1}, x_{i+1}^{n+1}, \ldots, x_{k}^{n+1}, x_{1}^{n+1}, \ldots, x_{i-1}^{n+1}\right)\right) \\
\leq & \varphi\left(\left(d\left(g\left(x_{i}^{n}\right), g\left(x_{i}^{n+1}\right)\right)+\cdots+d\left(g\left(x_{k}^{n}\right), g\left(x_{k}^{n+1}\right)\right)\right.\right. \\
& \left.\left.+d\left(g\left(x_{1}^{n}\right), g\left(x_{1}^{n+1}\right)\right)+\cdots+d\left(g\left(x_{i-1}^{n}\right), g\left(x_{i-1}^{n+1}\right)\right)\right) / k\right) \\
\leq & \varphi\left(\frac{\delta_{n}}{k}\right) .
\end{aligned}
$$

Summing, we get

$$
\delta_{n+1}=d\left(g\left(x_{1}^{n+1}\right), g\left(x_{1}^{n+2}\right)\right)+d\left(g\left(x_{2}^{n+1}\right), g\left(x_{2}^{n+2}\right)\right)+\cdots+d\left(g\left(x_{k}^{n+1}\right), g\left(x_{k}^{n+2}\right)\right) \leq k \varphi\left(\frac{\delta_{n}}{k}\right) .
$$

If for some $n$ we have $\delta_{n}=0$, then $\delta_{n+1}=0$; otherwise, $\delta_{n}>0$ for all $n \in \mathbb{N}$, then

$$
\delta_{n+1} \leq k \varphi\left(\frac{\delta_{n}}{k}\right)<k \frac{\delta_{n}}{k}=\delta_{n}
$$

Hence $\left\{\delta_{n}\right\}$ is a non-increasing sequence which is bounded below $\left(0 \leq \delta_{n}\right)$, then there exits some $\delta \geq 0$ such that

$$
\lim _{n \rightarrow \infty} \delta_{n}=\delta .
$$

We will show that $\delta=0$. If for some $n, \delta_{n}=0$, it is obvious; otherwise, suppose that $\delta>0$. Keeping in mind that $\lim _{r \rightarrow t^{+}} \varphi(r)<t$ (for all $t>0$ ) and taking the limit as $\delta_{n} \rightarrow \delta$ of both sides of (2.6), we have

$$
\delta=\lim _{n \rightarrow \infty} \delta_{n+1}<\lim _{n \rightarrow \infty} k \varphi\left(\frac{\delta_{n}}{k}\right)=\lim _{\delta_{n} \rightarrow \delta} k \varphi\left(\frac{\delta_{n}}{k}\right)<k \varphi\left(\frac{\delta}{k}\right)<k \frac{\delta}{k}=\delta
$$

which is contradiction. Thus $\delta=0$, that is,

$$
\lim _{n \rightarrow \infty} d\left(g\left(x_{1}^{n}\right), g\left(x_{1}^{n+1}\right)\right)+d\left(g\left(x_{2}^{n}\right), g\left(x_{2}^{n+1}\right)\right)+\cdots+d\left(g\left(x_{k}^{n}\right), g\left(x_{k}^{n+1}\right)\right)=0 .
$$


Now, we will show that $\left\{g\left(x_{i}^{n}\right)\right\}_{n \in \mathbb{N}}$ for all $i \in\{1,2, \ldots, k\}$ is a Cauchy sequence. Suppose, on the contrary, that at least one of $\left\{g\left(x_{i}^{n}\right)\right\}(i \in\{1,2, \ldots, k\})$ is not Cauchy. So, there exists $\epsilon>0$ for which we can find sub-sequences $\left\{g\left(x_{i}^{n(l)}\right)\right\},\left\{g\left(x_{i}^{m(l)}\right)\right\}$ of $\left\{g\left(x_{i}^{n}\right)\right\}$ with $n(l)>m(l) \geq l$ such that

$$
\sum_{i=1}^{k} d\left(g\left(x_{i}^{n(l)}\right), g\left(x_{i}^{m(l)}\right)\right) \geq \epsilon
$$

We can choose $n(l)$, corresponding to $m(l)$, such that it is the smallest integer satisfying (2.8) and $n(l)>m(l) \geq l$. Hence

$$
\sum_{i=1}^{k} d\left(g\left(x_{i}^{n(l)-1}\right), g\left(x_{i}^{m(l)}\right)\right)<\epsilon
$$

Due to (2.8), (2.9) and by using the triangle inequality, we have

$$
\begin{aligned}
\epsilon & \leq t_{l}:=\sum_{i=1}^{k} d\left(g\left(x_{i}^{n(l)}\right), g\left(x_{i}^{m(l)}\right)\right) \\
& \leq \sum_{i=1}^{k}\left(d\left(g\left(x_{i}^{n(l)}\right), g\left(x_{i}^{n(l)-1}\right)\right)\right)+\sum_{i=1}^{k}\left(d\left(g\left(x_{i}^{n(l)-1}\right), g\left(x_{i}^{m(l)}\right)\right)\right) \\
& <\sum_{i=1}^{k}\left(d\left(g\left(x_{i}^{n(l)}\right), g\left(x_{i}^{n(l)-1}\right)\right)+\epsilon .\right.
\end{aligned}
$$

Taking $l \rightarrow \infty$ in (2.10) and using (2.7), we have

$$
\epsilon<\liminf _{l \rightarrow \infty}\left(\sum_{i=1}^{k} d\left(g\left(x_{i}^{n(l)}\right), g\left(x_{i}^{n(l)-1}\right)\right)\right)+\epsilon=\epsilon .
$$

That is a contradiction. Therefore $\left\{g\left(x_{i}^{n}\right)\right\}$ for all $i \in\{1,2, \ldots, k\}$ are Cauchy sequences.

Since $X$ is a complete metric space, there exist $x_{1}, x_{2}, \ldots, x_{k} \in X$ such that

$$
\lim _{n \rightarrow \infty} g\left(x_{i}^{n}\right)=x_{i}
$$

for all $i \in\{1,2, \ldots, k\}$. Due to the continuity of $g,(2.11)$ implies that

$$
\lim _{n \rightarrow \infty} g\left(g\left(x_{i}^{n}\right)\right)=g\left(x_{i}\right) \quad \text { for all } i \in\{1,2, \ldots, k\}
$$

By (2.4) and the commutativity of $F$ and $g$, we have

$$
\begin{aligned}
g\left(g\left(x_{i}^{n+1}\right)\right) & =g\left(F\left(x_{i}^{n}, x_{i+1}^{n}, \ldots, x_{k}^{n}, x_{1}^{n}, \ldots, x_{i-1}^{n}\right)\right) \\
& =F\left(g\left(x_{i}^{n}\right), g\left(x_{i+1}^{n}\right), \ldots, g\left(x_{k}^{n}\right), g\left(x_{1}^{n}\right), \ldots, g\left(x_{i-1}^{n}\right)\right)
\end{aligned}
$$

for all $i \in\{1,2, \ldots, k\}$. We will show that

$$
F\left(x_{i}, x_{i+1}, \ldots, x_{k}, x_{1}, x_{2}, \ldots, x_{i-1}\right)=g\left(x_{i}\right) .
$$


We consider the following two cases.

Case I: The assumption (a) holds. Then by (2.4), (2.13) and (2.11), we have

$$
\begin{aligned}
g\left(x_{i}\right) & =\lim _{n \rightarrow \infty} g\left(g\left(x_{i}^{n+1}\right)\right)=\lim _{n \rightarrow \infty} g\left(F\left(x_{i}^{n}, x_{i+1}^{n}, \ldots, x_{k}^{n}, x_{1}^{n}, \ldots, x_{i-1}^{n}\right)\right) \\
& =\lim _{n \rightarrow \infty} F\left(g\left(x_{i}^{n}\right), g\left(x_{i+1}^{n}\right), \ldots, g\left(x_{k}^{n}\right), g\left(x_{1}^{n}\right), \ldots, g\left(x_{i-1}^{n}\right)\right) \\
& =F\left(x_{i}, x_{i+1}, \ldots, x_{k}, x_{1}, \ldots, x_{i-1}\right)
\end{aligned}
$$

for all $i \in\{1,2, \ldots, k\}$. Thus (2.14) is proved.

Case II: The assumption (b) holds. Since $\left\{g\left(x_{2 i-1}^{n}\right)\right\}$ is non-decreasing for all $i \in\{1,2$, $\left.\ldots,\left[\frac{k+1}{2}\right]\right\}$ and $g\left(x_{2 i-1}^{n}\right) \rightarrow x_{2 i-1}$, and also $\left\{g\left(x_{2 i}^{n}\right)\right\}$ is non-increasing for all $i \in\left\{1,2, \ldots,\left[\frac{k}{2}\right]\right\}$ and $g\left(x_{2 i}^{n}\right) \rightarrow x_{2 i}$, then by assumption (b) we have

$$
\begin{aligned}
& g\left(x_{2 i-1}^{n}\right) \leq x_{2 i-1} \quad \text { for all } i \in\left\{1,2, \ldots,\left[\frac{k+1}{2}\right]\right\}, \\
& g\left(x_{2 i}^{n}\right) \geq x_{2 i} \text { for all } i \in\left\{1,2, \ldots,\left(\left[\frac{k}{2}\right]\right)\right\}
\end{aligned}
$$

for all $n$. Thus by (2.13), (2.1) and the triangle inequality,

$$
\begin{aligned}
& d\left(g\left(x_{i}\right), F\left(x_{i}, x_{i+1}, \ldots, x_{k}, x_{1}, x_{2}, \ldots, x_{i-1}\right)\right) \\
& \leq d\left(g\left(x_{i}\right), g\left(g\left(x_{i}^{n+1}\right)\right)\right)+d\left(g\left(g\left(x_{i}^{n+1}\right)\right), F\left(x_{i}, x_{i+1}, \ldots, x_{k}, x_{1}, x_{2}, \ldots, x_{i-1}\right)\right) \\
&= d\left(g\left(x_{i}\right), g\left(g\left(x_{i}^{n+1}\right)\right)\right)+d\left(g\left(F\left(x_{i}^{n}, x_{i+1}^{n}, \ldots, x_{k}^{n}, x_{1}^{n}, x_{2}^{n}, \ldots, x_{i-1}^{n}\right)\right),\right. \\
&\left.F\left(x_{i}, x_{i+1}, \ldots, x_{k}, x_{1}, x_{2}, \ldots, x_{i-1}\right)\right) \\
&= d\left(g\left(x_{i}\right), g\left(g\left(x_{i}^{n+1}\right)\right)\right)+d\left(F\left(g\left(x_{i}^{n}\right), g\left(x_{i+1}^{n}\right), \ldots, g\left(x_{k}^{n}\right), g\left(x_{1}^{n}\right), g\left(x_{2}^{n}\right), \ldots, g\left(x_{i-1}^{n}\right)\right),\right. \\
&\left.F\left(x_{i}, x_{i+1}, \ldots, x_{k}, x_{1}, x_{2}, \ldots, x_{i-1}\right)\right) \\
& \leq d\left(g\left(x_{i}\right), g\left(g\left(x_{i}^{n+1}\right)\right)\right)+\varphi\left(\frac { 1 } { k } \left[d\left(g\left(g\left(x_{i}^{n}\right)\right), g\left(x_{i}\right)\right)+d\left(g\left(g\left(x_{i+1}^{n}\right)\right), g\left(x_{i+1}\right)\right)\right.\right. \\
&\left.\left.+\cdots+d\left(g\left(g\left(x_{k}^{n}\right)\right), g\left(x_{k}\right)\right)+d\left(g\left(g\left(x_{1}^{n}\right)\right), g\left(x_{1}\right)\right)+\cdots+d\left(g\left(g\left(x_{i-1}^{n}\right)\right), g\left(x_{i-1}\right)\right)\right]\right)
\end{aligned}
$$

for all $i \in\{1,2, \ldots, k\}$. Taking the limit as $n \rightarrow \infty$, by (2.12) and the fact that $\varphi(0)=0$, we get $d\left(g\left(x_{i}\right), F\left(x_{i}, x_{i+1}, \ldots, x_{k}, x_{1}, \ldots, x_{i-1}\right)\right) \leq 0$. Thus

$$
g\left(x_{i}\right)=F\left(x_{i}, x_{i+1}, \ldots, x_{k}, x_{1}, x_{2}, \ldots, x_{i-1}\right) \quad \text { for all } i \in\{1,2, \ldots, k\} .
$$

Hence we proved that $F$ and $g$ have a $k$-coincidence point.

Corrollary 2.6 Let $F: X^{k} \rightarrow X$ and $g: X \rightarrow X$ be a continuous mapping such that $F$ has a new $g$-monotone property, $F\left(X^{k}\right) \subset g(X)$ and $g$ commutes with $F$. Assume that there exists $l \in[0,1)$ with

$$
d\left(F\left(x_{1}, x_{2}, \ldots, x_{k}\right), F\left(y_{1}, y_{2}, \ldots, y_{k}\right)\right) \leq \frac{l}{k}\left[d\left(g\left(x_{1}\right), g\left(y_{1}\right)\right)+\cdots+d\left(g\left(x_{k}\right), g\left(y_{k}\right)\right)\right]
$$


for all $x_{j}, y_{j}(j \in\{1,2, \ldots, k\})$ which $g\left(x_{2 i-1}\right) \leq g\left(y_{2 i-1}\right)$ for all $i \in\left\{1,2, \ldots,\left[\frac{k+1}{2}\right]\right\}$ and $g\left(y_{2 i}\right) \leq$ $g\left(x_{2 i}\right)$ for all $i \in\left\{1,2, \ldots,\left[\frac{k}{2}\right]\right\}$, and suppose that there exist $x_{1}^{0}, x_{2}^{0}, \ldots, x_{k}^{0} \in X$ such that

$$
\begin{aligned}
& g\left(x_{2 i-1}^{0}\right) \leq F\left(x_{2 i-1}^{0}, x_{2 i}^{0}, \ldots, x_{k}^{0}, x_{1}^{0}, \ldots, x_{2 i-2}^{0}\right) \quad \text { for all } i \in\left\{1,2, \ldots,\left[\frac{k+1}{2}\right]\right\}, \\
& g\left(x_{2 i}^{0}\right) \geq F\left(x_{2 i}^{0}, x_{2 i+1}^{0}, \ldots, x_{k}^{0}, x_{1}^{0}, x_{2}^{0}, \ldots, x_{2 i-1}^{0}\right) \quad \text { for all } i \in\left\{1,2, \ldots,\left[\frac{k}{2}\right]\right\},
\end{aligned}
$$

and suppose either

(a) $F$ is continuous, or

(b) $X$ has the following property:

(i) If a non-decreasing sequence $\left\{x_{n}\right\} \rightarrow x$, then $x_{n} \leq x$ for all $n$;

(ii) If a non-increasing sequence $\left\{y_{n}\right\} \rightarrow y$, then $y \leq y_{n}$ for all $n$.

Then there exist $x_{1}, x_{2}, \ldots, x_{k} \in X$ such that

$$
g\left(x_{i}\right)=F\left(x_{i}, x_{i+1}, \ldots, x_{n}, x_{1}, x_{2}, \ldots, x_{i-1}\right) \quad \text { for all } i \in\{1,2, \ldots, k\} .
$$

That is, $F$ and $g$ have a $k$-coincidence point.

Proof It follows from Theorem 2.5 by putting $\varphi(t)=l \cdot t$ for $l \in[0,1)$.

Example 2.7 Let $X=\mathbb{R}, d(x, y)=|x-y|, k \in \mathbb{N}, k>1$, and let $F: X^{k} \rightarrow X$ be defined by

$$
F\left(x_{1}, x_{2}, \ldots, x_{k}\right)=\frac{(k+1) \sum_{j=1}^{k-1}(-1)^{j-1} x_{j}+k(-1)^{k-1} x_{k}+1}{2 k(k+1)}
$$

for all $x_{1}, x_{2}, \ldots, x_{k} \in X$. It is easy to check that $F$ satisfies Corollary 2.6 by taking $\varphi(t)=\frac{t}{2}$ and $g=i d_{X}$. If $k$ is an odd positive integer, then

$$
\underbrace{(\underbrace{k(2 k+1)}, \frac{1}{k(2 k+1)}, \ldots, \frac{1}{k(2 k+1)}, \ldots, \frac{1}{k(2 k+1)})}_{k \text {-times }}
$$

is the $k$-fixed point of $F$, and if $k$ is an even positive integer, then

$$
(\underbrace{\left.\frac{1}{2 k(k+1)-1}, \frac{1}{2 k(k+1)-1}, \ldots, \frac{1}{2 k(k+1)-1}, \ldots, \frac{1}{2 k(k+1)-1}\right)}_{k \text {-times }}
$$

is the $k$-fixed point of $F$.

Theorem 2.8 In addition to the hypothesis of Theorem 2.5, suppose that for every

$$
\left(x_{1}, x_{2}, \ldots, x_{k}\right),\left(x_{1}^{*}, x_{2}^{*}, \ldots, x_{k}^{*}\right) \in X^{k}
$$

there exists $\left(u_{1}, u_{2}, \ldots, u_{k}\right) \in X^{k}$ such that

$$
\left(F\left(u_{1}, \ldots, u_{k}\right), F\left(u_{2}, \ldots, u_{k}, u_{1}\right), \ldots, F\left(u_{i}, \ldots, u_{k}, u_{1}, \ldots, u_{i-1}\right), \ldots, F\left(u_{k}, u_{1}, \ldots, u_{k-1}\right)\right)
$$


is comparable to

$$
\begin{aligned}
& \left(F\left(x_{1}, \ldots, x_{k}\right), F\left(x_{2}, \ldots, x_{k}, x_{1}\right), \ldots,\right. \\
& \left.\quad F\left(x_{i}, \ldots, x_{k}, x_{1}, \ldots, x_{i-1}\right), \ldots, F\left(x_{k}, x_{1}, \ldots, x_{k-1}\right)\right)
\end{aligned}
$$

and

$$
\begin{aligned}
& \left(F\left(x_{1}^{*}, \ldots, x_{k}^{*}\right), F\left(x_{2}^{*}, \ldots, x_{k}^{*}, x_{1}^{*}\right), \ldots,\right. \\
& \left.\quad F\left(x_{i}^{*}, \ldots, x_{k}^{*}, x_{1}^{*}, \ldots, x_{i-1}^{*}\right), \ldots, F\left(x_{k}^{*}, x_{1}^{*}, \ldots, x_{k-1}^{*}\right)\right) .
\end{aligned}
$$

Then $F$ and $g$ have a unique $k$-coincidence point, which is a fixed point of $g: X \rightarrow X$ and $a$ $k$-fixed point of $F: X^{k} \rightarrow X$. That is, there exists a unique $\left(x_{1}, x_{2}, \ldots, x_{k}\right) \in X^{k}$ such that

$$
x_{i}=g\left(x_{i}\right)=F\left(x_{i}, x_{i+1}, \ldots, x_{k}, x_{1}, x_{2}, \ldots, x_{i-1}\right) \text { for all } i \in\{1,2, \ldots, k\}
$$

Proof By Theorem 2.5, the set of $k$-coincidence fixed points is nonempty. Now, suppose $\left(x_{1}, x_{2}, \ldots, x_{k}\right)$ and $\left(x_{1}^{*}, x_{2}^{*}, \ldots, x_{k}^{*}\right)$ are two coincidence fixed points of $F$ and $g$, that is,

$$
\begin{aligned}
& g\left(x_{i}\right)=F\left(x_{i}, x_{i+1}, \ldots, x_{k}, x_{1}, x_{2}, \ldots, x_{i-1}\right) \quad \text { for all } i \in\{1,2, \ldots, k\}, \\
& g\left(x_{i}^{*}\right)=F\left(x_{i}^{*}, x_{i+1}^{*}, \ldots, x_{k}^{*}, x_{1}^{*}, x_{2}^{*}, \ldots, x_{i-1}^{*}\right) \text { for all } i \in\{1,2, \ldots, k\} .
\end{aligned}
$$

We will show that

$$
g\left(x_{i}\right)=g\left(x_{i}^{*}\right) \text { for all } i \in\{1,2, \ldots, k\}
$$

By assumption, there exists $\left(u_{1}, u_{2}, \ldots, u_{k}\right) \in X^{k}$ such that

$$
\begin{aligned}
& \left(F\left(u_{1}, \ldots, u_{k}\right), F\left(u_{2}, \ldots, u_{k}, u_{1}\right), \ldots,\right. \\
& \left.\quad F\left(u_{i}, \ldots, u_{k}, u_{1}, \ldots, u_{i-1}\right), \ldots, F\left(u_{k}, u_{1}, \ldots, u_{k-1}\right)\right)
\end{aligned}
$$

is comparable with

$$
\begin{aligned}
& \left(F\left(x_{1}, \ldots, x_{k}\right), F\left(x_{2}, \ldots, x_{k}, x_{1}\right), \ldots,\right. \\
& \left.\quad F\left(x_{i}, \ldots, x_{k}, x_{1}, x_{2}, \ldots, x_{i-1}\right), \ldots, F\left(x_{k}, x_{1}, \ldots, x_{k-1}\right)\right)
\end{aligned}
$$

and

$$
\begin{aligned}
& \left(F\left(x_{1}^{*}, \ldots, x_{k}^{*}\right), F\left(x_{2}^{*}, \ldots, x_{k}^{*}, x_{1}^{*}\right), \ldots,\right. \\
& \left.\quad F\left(x_{i}^{*}, \ldots, x_{k}^{*}, x_{1}^{*}, \ldots, x_{i-1}^{*}\right), \ldots, F\left(x_{k}^{*}, x_{1}^{*}, \ldots, x_{k-1}^{*}\right)\right) .
\end{aligned}
$$

Let $u_{i}^{0}:=u_{i}$ for all $i \in\{1,2, \ldots, k\}$.

Since $F\left(X^{k}\right) \subset g(X)$, we can choose $u_{i}^{1} \in X$ such that $g\left(u_{i}^{1}\right)=F\left(u_{i}^{0}, u_{i+1}^{0}, \ldots, u_{k}^{0}, u_{1}^{0}, \ldots, u_{i-1}^{0}\right)$ for all $i \in\{1,2, \ldots, k\}$. By a similar reason as in the proof of Theorem 2.5, we can inductively 
define sequences $\left\{g\left(u_{i}^{n}\right)\right\}_{n \in \mathbb{N}}$ for all $i \in\{1,2, \ldots, k\}$ such that for all $n \in \mathbb{N} \cup\{0\}$,

$$
g\left(u_{i}^{n+1}\right)=F\left(u_{i}^{n}, u_{i+1}^{n}, \ldots, u_{k}^{n}, u_{1}^{n}, \ldots, u_{i-1}^{n}\right) \quad \text { for all } i \in\{1,2, \ldots, k\} .
$$

In addition, let $x_{i}^{0}:=x_{i}$ and $x_{i}^{*^{0}}:=x_{i}^{*}$ for all $i \in\{1,2, \ldots, k\}$ and, in the same way, define the sequences $\left\{g\left(x_{i}^{n}\right)\right\}_{n \in \mathbb{N}}$ and $\left\{g\left(x_{i}^{*^{n}}\right)\right\}_{n \in \mathbb{N}}$ for all $i \in\{1,2, \ldots, k\}$. Since

$$
\begin{aligned}
& \left(F\left(x_{1}, \ldots, x_{k}\right), F\left(x_{2}, \ldots, x_{k}, x_{1}\right), \ldots, F\left(x_{i}, \ldots, x_{k}, x_{1}, \ldots, x_{i-1}\right), \ldots, F\left(x_{k}, x_{1}, \ldots, x_{k-1}\right)\right) \\
& \quad=\left(g\left(x_{1}^{1}\right), g\left(x_{2}^{1}\right), \ldots, g\left(x_{i}^{1}\right), \ldots, g\left(x_{k}^{1}\right)\right)
\end{aligned}
$$

and

$$
\begin{aligned}
& \left(F\left(u_{1}, \ldots, u_{k}\right), F\left(u_{2}, \ldots, u_{k}, u_{1}\right), \ldots, F\left(u_{i}, \ldots, u_{k}, u_{1}, \ldots, u_{i-1}\right), \ldots, F\left(u_{k}, u_{1}, \ldots, u_{k-1}\right)\right) \\
& \quad=\left(g\left(u_{1}^{1}\right), g\left(u_{2}^{1}\right), \ldots, g\left(u_{i}^{1}\right), \ldots, g\left(u_{k}^{1}\right)\right)
\end{aligned}
$$

are comparable, then

$$
\begin{aligned}
& g\left(x_{2 i-1}^{1}\right) \leq g\left(u_{2 i-1}^{1}\right) \quad \text { for all } i \in\left\{1,2, \ldots,\left[\frac{k+1}{2}\right]\right\}, \\
& g\left(x_{2 i}^{1}\right) \geq g\left(u_{2 i}^{1}\right) \quad \text { for all } i \in\left\{1,2, \ldots,\left[\frac{k}{2}\right]\right\}
\end{aligned}
$$

Now, for all $n \in \mathbb{N}$, we have

$$
\begin{aligned}
& g\left(x_{2 i-1}\right)=g\left(x_{2 i-1}^{1}\right) \leq g\left(u_{2 i-1}^{1}\right) \leq g\left(u_{2 i-1}^{2}\right) \leq \cdots \leq g\left(u_{2 i-1}^{n}\right) \quad\left(i \in\left\{1,2, \ldots,\left[\frac{k+1}{2}\right]\right\}\right), \\
& g\left(x_{2 i}\right)=g\left(x_{2 i}^{1}\right) \geq g\left(u_{2 i}^{1}\right) \geq g\left(u_{2 i}^{2}\right) \geq \cdots \geq g\left(u_{2 i}^{n}\right) \quad\left(i \in\left\{1,2, \ldots,\left[\frac{k}{2}\right]\right\}\right) .
\end{aligned}
$$

Then $\left(g\left(x_{1}\right), g\left(x_{2}\right), \ldots, g\left(x_{k}\right)\right)$ and $\left(g\left(u_{1}^{n}\right), g\left(u_{2}^{n}\right), \ldots, g\left(u_{k}^{n}\right)\right)$ are comparable for all $n \in \mathbb{N}$.

It follows from (2.1) that

$$
\begin{aligned}
d( & \left.g\left(x_{2 i-1}\right), g\left(u_{2 i-1}^{n+1}\right)\right) \\
= & d\left(F\left(x_{2 i-1}, x_{2 i}, \ldots, x_{k}, x_{1}, \ldots, x_{2 i-2}\right), F\left(u_{2 i-1}^{n}, u_{2 i}^{n}, \ldots, u_{k}^{n}, u_{1}^{n}, \ldots, u_{2 i-2}^{n}\right)\right) \\
\leq & \varphi\left(\left(d\left(g\left(x_{2 i-1}\right), g\left(u_{2 i-1}^{n}\right)\right)+\cdots+d\left(g\left(x_{k}\right), g\left(u_{k}^{n}\right)\right)+d\left(g\left(x_{1}\right), g\left(u_{1}^{n}\right)\right)\right.\right. \\
& \left.\left.+\cdots+d\left(g\left(x_{2 i-2}\right), g\left(u_{2 i-2}^{n}\right)\right)\right) / k\right)
\end{aligned}
$$

for all $i \in\left\{1,2, \ldots,\left[\frac{k+1}{2}\right]\right\}$ and

$$
\begin{aligned}
d( & \left.g\left(x_{2 i}\right), g\left(u_{2 i}^{n+1}\right)\right) \\
= & d\left(F\left(x_{2 i}, x_{2 i+1}, \ldots, x_{k}, x_{1}, \ldots, x_{2 i-1}\right), F\left(u_{2 i}^{n}, u_{2 i+1}^{n}, \ldots, u_{k}^{n}, u_{1}^{n}, \ldots, u_{2 i-1}^{n}\right)\right) \\
\leq & \varphi\left(\left(d\left(g\left(x_{2 i}\right), g\left(u_{2 i}^{n}\right)\right)+\cdots+d\left(g\left(x_{k}\right), g\left(u_{k}^{n}\right)\right)+d\left(g\left(x_{1}\right), g\left(u_{1}^{n}\right)\right)\right.\right. \\
& \left.\left.+\cdots+d\left(g\left(x_{2 i-1}\right), g\left(u_{2 i-1}^{n}\right)\right)\right) / k\right)
\end{aligned}
$$

for all $i \in\left\{1,2, \ldots,\left(\left[\frac{k}{2}\right]\right)\right\}$. 
Summing, we get

$$
\begin{array}{r}
\frac{1}{k}\left[d\left(g\left(x_{1}\right), g\left(u_{1}^{n+1}\right)\right)+d\left(g\left(x_{2}\right), g\left(u_{2}^{n+1}\right)\right)+\cdots+d\left(g\left(x_{k}\right), g\left(u_{k}^{n+1}\right)\right)\right] \\
\leq \frac{k}{k} \varphi\left(\frac{d\left(g\left(x_{1}\right), g\left(u_{1}^{n}\right)\right)+d\left(g\left(x_{2}\right), g\left(u_{2}^{n}\right)\right)+\cdots+d\left(g\left(x_{k}\right), g\left(u_{k}^{n}\right)\right)}{k}\right) .
\end{array}
$$

It follows that

$$
\begin{array}{r}
\frac{1}{k}\left[d\left(g\left(x_{1}\right), g\left(u_{1}^{n+1}\right)\right)+d\left(g\left(x_{2}\right), g\left(u_{2}^{n+1}\right)\right)+\cdots+d\left(g\left(x_{k}\right), g\left(u_{k}^{n+1}\right)\right)\right] \\
\leq \varphi^{n}\left(\frac{d\left(g\left(x_{1}\right), g\left(u_{1}\right)\right)+d\left(g\left(x_{2}\right), g\left(u_{2}\right)\right)+\cdots+d\left(g\left(x_{k}\right), g\left(u_{k}\right)\right)}{k}\right)
\end{array}
$$

for all $n \geq 1$. Note that $\varphi(0)=0, \varphi(t)<t, \lim _{r \rightarrow t^{+}} \varphi(r)<t$ for $t>0$ imply that $\lim _{n \rightarrow \infty} \varphi^{n}(t)=$ 0 for all $t>0$. Hence from (2.16) we have

$$
\lim _{n \rightarrow \infty} d\left(g\left(x_{i}\right), g\left(u_{i}^{n+1}\right)\right)=0 \quad \text { for all } i \in\{1,2, \ldots, k\}
$$

Similarly, one can prove that

$$
\lim _{n \rightarrow \infty} d\left(g\left(x_{i}^{*}\right), g\left(u_{i}^{n+1}\right)\right)=0 \quad \text { for all } i \in\{1,2, \ldots, k\}
$$

It follows from (2.17), (2.18) and the triangle inequality that

$$
d\left(g\left(x_{i}\right), g\left(x_{i}^{*}\right)\right) \leq d\left(g\left(x_{i}\right), g\left(u_{i}^{n+1}\right)\right)+d\left(g\left(u_{i}^{n+1}\right), g\left(x_{i}^{*}\right)\right) \rightarrow 0,
$$

as $n \rightarrow \infty$ for all $i \in\{1,2, \ldots, k\}$. Hence $g\left(x_{i}\right)=g\left(x_{i}^{*}\right)$, therefore (2.15) is proved.

Since $g\left(x_{i}\right)=F\left(x_{i}, x_{i+1}, \ldots, x_{k}, x_{1}, x_{2}, \ldots, x_{i-1}\right)$ for all $i \in\{1,2, \ldots, k\}$, by the commutativity of $F$ and $g$, we have

$$
\begin{aligned}
g\left(g\left(x_{i}\right)\right) & =g\left(F\left(x_{i}, x_{i+1}, \ldots, x_{k}, x_{1}, x_{2}, \ldots, x_{i-1}\right)\right) \\
& =F\left(g\left(x_{i}\right), g\left(x_{i+1}\right), \ldots, g\left(x_{k}\right), g\left(x_{1}\right), \ldots, g\left(x_{i-1}\right)\right) .
\end{aligned}
$$

Denote $g\left(x_{i}\right)=y_{i}$ for all $i \in\{1,2, \ldots, k\}$. From (2.19), we have

$$
g\left(y_{i}\right)=g\left(g\left(x_{i}\right)\right)=F\left(y_{i}, y_{i+1}, \ldots, y_{k}, y_{1}, \ldots, y_{i-1}\right) \quad \text { for all } i \in\{1,2, \ldots, k\}
$$

Hence $\left(y_{1}, y_{2}, \ldots, y_{k}\right)$ is a $k$-coincidence point of $F$ and $g$.

It follows from (2.15) and $x_{i}^{*}=y_{i}$ that

$$
g\left(y_{i}\right)=g\left(x_{i}\right) \quad \text { for all } i \in\{1,2, \ldots, k\}
$$

This means that

$$
g\left(y_{i}\right)=y_{i} \quad \text { for all } i \in\{1,2, \ldots, k\} .
$$


Now, from (2.20) we have

$$
y_{i}=g\left(y_{i}\right)=F\left(y_{i}, y_{i+1}, \ldots, y_{k}, y_{1}, \ldots, y_{i-1}\right) \quad \text { for all } i \in\{1,2, \ldots, k\}
$$

Hence, $\left(y_{1}, y_{2}, \ldots, y_{k}\right)$ is a $k$-fixed point of $F$ and a fixed point of $g$.

To prove the uniqueness of the fixed point, assume that $\left(z_{1}, z_{2}, \ldots, z_{k}\right)$ is another $k$-fixed point. Then by (2.15) we have

$$
z_{i}=g\left(z_{i}\right)=g\left(y_{i}\right)=y_{i} \quad \text { for all } i \in\{1,2, \ldots, k\} .
$$

Thus $\left(z_{1}, z_{2}, \ldots, z_{k}\right)=\left(y_{1}, y_{2}, \ldots, y_{k}\right)$. This completes the proof.

\section{Competing interests}

The authors declare that they have no competing interests.

\section{Authors' contributions}

All authors read and approved the final manuscript.

\section{Author details}

${ }^{1}$ Department of Mathematics, Science and Research Branch, Islamic Azad University, Tehran, Iran. ${ }^{2}$ Department of Mathematics, Semnan University, P.O. Box 35195-363, Semnan, Iran. ${ }^{3}$ Institute of Research and Development of Processes, University of Basque Country, Campus of Leioa (Bizkaia) - Aptdo. 644, Bilbao, 48080, Spain. ${ }^{4}$ Departement of Mathematics and Computer Sciences, Amirkabir University of Technology, Hafez Ave., P.O. Box 15914, Tehran, Iran.

\section{Acknowledgements}

The authors are very grateful to the Spanish Government for its support of this research through Grant DPI2012-30651 and to the Basque Government for its support of this research through Grant IT378-10. They also grateful to the University of Basque Country for Grant UFI 2011/07.

\section{Received: 14 July 2012 Accepted: 11 April 2013 Published: 25 April 2013}

\section{References}

1. Bhaskar, TG, Lakshmikantham, V: Fixed point theorems in partially ordered metric spaces and applications. Nonlinear Anal. 65, 1379-1393 (2006)

2. Lakshmikantham, V, Ćirić, L: Coupled fixed point theorems for nonlinear contractions in partially ordered metric spaces. Nonlinear Anal. 70, 4341-4349 (2009)

3. Eshaghi Gordji, M, Baghani, H, Cho, YJ: Coupled fixed point theorems for contractions in intuitionistic fuzzy normed spaces. Math. Comput. Model. 54(9-10), 1897-1906 (2011)

4. Samet, B, Vetro, C: Coupled fixed point, $f$-invariant set and fixed point of $\mathrm{N}$-order. Ann. Funct. Anal. 1(2), $46-56$ (2010)

5. Abbas, M, Ćirić, L, Damjanović, B, Khan, MA: Coupled coincidence and common fixed point theorems for hybrid pair of mappings. Fixed Point Theory Appl. 2012, Article ID 4 (2012)

6. Ćirić, L, Damjanović, B, Jeli, M, Samet, B: Coupled fixed point theorems for generalized Mizoguchi-Takahashi contraction and applications to ordinary differential equations. Fixed Point Theory Appl. 2012, Article ID 51 (2012)

7. Ćirić, L, Olatinwo, MO, Gopal, D, Akinbo, G: Coupled fixed point theorems for mappings satisfying a contractive condition of rational type on a partially ordered metric space. Adv. Fixed Point Theory 2(1), 1-8 (2012)

8. Nashine, HK, Shatanawi, W: Coupled common fixed point theorems for a pair of commuting mappings in partially ordered complete metric spaces. Comput. Math. Appl. 62, 1984-1993 (2011)

9. Ćirić, L, Mihet, D, Saadati, R: Monotone generalized contractions in partially ordered probabilistic metric spaces. Topol. Appl. 156, 2838-2844 (2009)

10. Ćirić, L, Hussain, N, Cakić, N: Common fixed points for C'iric type $f$-weak contraction with applications. Publ. Math. (Debr.) 76(1-2), 31-49 (2010)

11. Ćirić, L, Abbas, M, Saadati, R, Hussain, N: Common fixed points of almost generalized contractive mappings in ordered metric spaces. Appl. Math. Comput. 217, 5784-5789 (2011)

12. Ćirić, L, Samet, B, Cakić, N, Damjanović, B: Generalized $(\psi, \omega)$-weak nonlinear contractions in ordered K-metric spaces. Comput. Math. Appl. 62, 3305-3316 (2011)

13. Eshaghi Gordji, M, Ramezani, M: A generalization of Mizoguchi and Takahashi's theorem for single-valued mappings in partially ordered metric spaces. Nonlinear Anal. 74(13), 4544-4549 (2011)

14. Berinde, V, Borcut, M: Tripled fixed point theorems for contractive type mappings in partially ordered metric spaces. Nonlinear Anal. 74, 4889-4897 (2011)

15. Borcut, $\mathrm{M}$, Berinde, $\mathrm{V}$ : Tripled coincidence theorems for contractive type mappings in partially ordered metric spaces Appl. Math. Comput. 218, 5929-5936 (2012)

16. Eshaghi Gordji, M, Ramezani, M: N-fixed point theorems in partially ordered metric spaces. Preprint 
doi:10.1186/1687-1812-2013-111

Cite this article as: Paknazar et al.: $N$-fixed point theorems for nonlinear contractions in partially ordered metric spaces. Fixed Point Theory and Applications 2013 2013:111.

Submit your manuscript to a SpringerOpen ${ }^{\circ}$ journal and benefit from:

- Convenient online submission

- Rigorous peer review

- Immediate publication on acceptance

Open access: articles freely available online

- High visibility within the field

- Retaining the copyright to your article

Submit your next manuscript at $\gg$ springeropen.com 